\title{
KECEMASAN DAN DEPRESI PADA PENDERITA DIABETES MELLITUS TIPE 2 YANG MENGALAMI DISFUNGSI SEKSUAL DI PUSKESMAS SIBELA KOTA SURAKARTA
}

\author{
Insiyah $^{1}$, Rini Tri Hastuti ${ }^{2}$ \\ 1,2 Poltekkes Kemenkes Surakarta Jurusan Keperawatan \\ Diterima : 4 Desember 2018, Disetujui : 11 Desember 2018 \\ Email: insiyahkamal@gmail.com
}

\begin{abstract}
Background: The various symptoms will be experienced by patients with diabetes mellitus type 2 following they suffers from the disease. The symptoms include the symptoms of anxiety and depression. During suffering from diabetes mellitus type 2 , the patients also experienced the complication of the disease that effect on the quality of life. Good management to the disease is very important to decrease mortality and morbidity. WHO stated that there is the increase of prevalence of diabetes mellitus type 2 in developing countries including Indonesia. This research aims to know the relationship between anxiety and depression to sexual dysfunction among woman with diabetes mellitus type 2 in Sibela Public Health Centre in Surakarta City. This research was also conducted to describe the level of anxiety, depression and sexual dysfunction among women with diabetes mellitus. Method: this research is non eksperimen with descriptive correlasional design that describe research based on the distribution and then find correlation between one variable and other variable. Chi Square SPSS (Statistical Program For Social Science) versi 18 was utilized to analyze the data. Result: showed that there correlation between anxiety and sexual dysfunction among women with diabetes mellitus with $p$ value $=0,002(p<0,05)$. Conclusion: There was also correlation between depression and sexual dysfunction among women with diabetes mellitus with $p$ value $=0.000(p<0,05)$. Identification of the symptoms of anxiety, depression, sexual dysfunction is important in order to plan appropriate intervention to deal with the problem.
\end{abstract}

Keywords: Anxiety, depression, sexual dysfunction, diabetes mellitus type 2

\section{PENDAHULUAN}

Berbagai gejala akan dialami oleh penderita diabetes mellitus dengan makin lamanya seseorang mengalaminya. Salah satu gejala yang muncul adalah gejala depresi dan kecemasan. Gejala depresi dan kecemasan berhubungan erat dengan jenis kelamin penderita diabetes tipe 2 dan indek masa tubuh (BMI). Semakin tinggi BMI menunjukkan gejala kecemasan dan depresi pada tingkat sedang sampai berat. Penderita mengalami kecemasan dengan frekuensi 3 kali lipat dibandingkan pria yaitu penderita $62 \%$ dan pria $21,5 \%$. Individu yang mengalami obesitas dengan BMI $>35$ mengalami kecemasan lebih sebanyak 52.5\% dan 35.4 $\%$ mengalami depresi dibandingkan dengan orang lain dengan kelebihan berat badan. Penderita beresiko 6 kali lipat 
mengalami gejala kecemasan sedang dan berat dan 3,3 kali lipat memiliki kemungkinan mengalami gejala depresi sedang sampai berat. (Roupa Z, Koulouri A, Sotiropoulou P, Makrinika E, Marneras X, Lahana I and Gourni M, 2014).

Terkait dengan status keluarga, janda dan penderita yang bercerai terlihat untuk lebih mengalami kecemasan sebagaimana bahwa kesendirian merupakan faktor resiko yang serius terjadinya mood disorder/ gangguan alam perasaan, sementara seorang yang menikah dan memiliki kebersamaan memiliki cara proaktif terhadap kecemasan dan depresi (Everson, S.A., Maty S.C., Lynch, J.W., Kaplan, G.A., 2002)

Sejalan dengan lamanya seseorang menderita diabetes mellitus maka muncullah beberapa komplikasi yang juga akan berdampak terhadap kualitas kehidupan secara keseluruhan. Penanganan yang baik terhadap penyakit ini sangat diperlukan dalam rangka mengurangi angka kesakitan dan kematian. WHO memastikan peningkatan penderita DM tipe 2 paling banyak akan terjadi di negara-negara berkembang termasuk Indonesia. Sebagian peningkatan jumlah penderita DM tipe 2 karena kurangnya pengetahuan tentang pengelolaan DM. Penderita DM yang mempunyai pengetahuan yang cukup tentang DM, kemudian selanjutnya mengubah perilakunya, akan dapat mengendalikan kondisi penyakitnya sehingga dapat hidup lebih lama. Inilah yang menyebabkan edukasi menjadi salah satu komponen penanganan DM (Witasari dkk, 2009).

Banyaknya jumlah pasien diabetes mellitus juga membutuhkan tindakan segera oleh berbagai pihak. Keluarga diharapkan secara proaktif menawarkan dukungan sosial yang lebih baik, dukungan emosional yang baik serta merasa bertanggung jawab untuk menghadapi anggota keluarga yang lain. Petugas kesehatan dituntut bekerja lebih keras dimulai dari pengkajian awal sebagai perencanaan akan tindakan yang tepat untuk mengatasinya. Puskesmas sebagai pusat layanan masyarakat di tingkat dasar memiliki andil dalam menanggulangi diabetes mellitus pada masyarakat. Puskesmas Sibela Kota Surakarta salah satunya, menangani 110 pasien diabetes mellitus yang datang untuk berobat. Berdasarkan hal tersebut di atas maka peneliti tertarik untuk melakukan penelitian dengan judul kecemasan, depresi, dan disfungsi seksual pada wanita penderita diabetes mellitus tipe 2 di puskesmas Sibela Kota Surakarta.

\section{METODE PENELITIAN}

Jenis penelitian ini adalah non eksperimen, dengan rancangan penelitian deskriptif korelasional yaitu suatu desain penelitian yang menggambarkan masalah penelitian berdasarkan distribusinya dan kemudian mencari hubungan antara variabel satu dengan variabel lain. Pendekatan yang digunakan dalam penelitian ini adalah pendekatan cross sectional yaitu suatu rancangan penelitian dimana pengukuran atau pengamatan terhadap variabel dependen dan independen dilakukan pada waktu bersamaan (Notoatmodjo, 2007).

Teknik sampling yang dipakai adalah teknik Total Sampling yaitu keseluruhan dari subjek penelitian (60 wanita penderita DM tipe 2) dilibatkan dalam penelitian (Sugiyono, 2002). Teknik ini dilakukan peneliti atas dasar 
selain hasilnya dapat menggambarkan keadaan sebenarnya dan jumlah tersebut masih dapat dijangkau dalam penelitian ini. Adapun syarat untuk menjadi sample adalah bila memenuhi kriteria sebagai berikut:

Kriteria inklusi:

1. Wanita menderita diabetes mellitus tipe 2

2. Usia produktif

Kriteria eksklusi:

1. Menderita diabetes mellitus tipe 1

2. Usia di atas 55 tahun

3. Usia di bawah 16 tahun

4. Mengalami disfungsi seksual sebelum menderita diabetes mellitus

Alat pengumpul data dalam penelitian ini berupa kuestioner dengan pertanyaan terstruktur yang terdiri dari lima bagian yang berisi informasi tentang: data demografi pada bagian A. Bagian $B$ berisi pertanyaan untuk menentukan tingkat kecemasan dan depresi responden yang merupakan kuesioner baku dari Zigmond, AS; Snaith, RP (1983) yang terdiri dari 7 pertanyaan dengan skala Likert tentang depresi dan 7 pertanyaan dengan skala Likert tentang kecemasan, Bagian C berisi pertanyaan tentang kemungkinan responden menderita disfungsi seksual yang dikembangkan dari Rosen, R., Brown, C., Heiman, J., Leiblum, S., Meston, C., Shabsigh, R., Ferguson, D., dan D'agostino, R. (2000) yang berisi 7 item pertanyaan utama.

\section{HASIL PENELITIAN}

1. Karakteristik sosial demografi pada pasien wanita diabetes mellitus tipe 2 di Puskesmas Sibela Kota Surakarta $(\mathrm{n}=60)$

Pada bagian ini disajikan hasil penelitian mengenai distribusi karakteristik sosial demografi pada pasien wanita diabetes mellitus tipe 2 di Puskesmas Sibela Kota Surakarta. Adapun distribusi karakteristik social demografi terdiri dari umur, pekerjaan, pendidikan terakhir pasien, lama menderita diabetes mellitus tipen 2, dan indeks masa tubuh (IMT).

Tabel 1. Distribusi frekuensi karakteristik social demografi pada pasien wanita diabetes mellitus tipe 2 di Puskesmas Sibela Surakarta $(\mathrm{N}=60)$.

\begin{tabular}{|c|c|c|c|}
\hline \multicolumn{2}{|c|}{$\begin{array}{c}\text { Karakteristik Sosial } \\
\text { demografi }\end{array}$} & \multirow{2}{*}{$\begin{array}{c}\mathbf{N} \\
0\end{array}$} & \multirow{2}{*}{$\begin{array}{c}\% \\
0,00\end{array}$} \\
\hline Usia & $<20$ & & \\
\hline & $20-55$ & 60 & 100,0 \\
\hline & $>55$ & 0 & 0,000 \\
\hline \multirow[t]{2}{*}{ Pekerjaan } & $\begin{array}{c}\text { Tidak } \\
\text { Bekeria }\end{array}$ & 48 & 80 \\
\hline & Bekerja & 12 & 20 \\
\hline \multirow{5}{*}{$\begin{array}{l}\text { Pendidikan } \\
\text { terakhir pasien }\end{array}$} & Tidak & 0 & 0,00 \\
\hline & SD & 6 & 10 \\
\hline & SLTP & 22 & 36,7 \\
\hline & SMU & 23 & 38,3 \\
\hline & $\begin{array}{c}\text { Perguruan } \\
\text { Tinggi }\end{array}$ & 9 & 15 \\
\hline \multirow{7}{*}{$\begin{array}{l}\text { Lama } \\
\text { menderita } \\
\text { diabetes } \\
\text { mellitus tipe2 } \\
\text { Indeks massa } \\
\text { tubuh (IMT) }\end{array}$} & $<5$ tahun & 38 & 63,3 \\
\hline & $\geq 5$ tahun & 22 & 36,7 \\
\hline & Kurang & 10 & 16,7 \\
\hline & Normal & 21 & 35,1 \\
\hline & Lebih & 19 & 31,7 \\
\hline & Obesitas 1 & 5 & 8,4 \\
\hline & Obesitas 2 & 5 & 8,4 \\
\hline
\end{tabular}

Dari tabel 1 diatas dapat diketahui bahwa umur berkisar 45 - 55 tahun, pekerjaan Tidak Bekerja $(80 \%)$, mayoritas pendidikan terakhir pasien SMA $(38,3 \%)$, lama menderita diabetes mellitus tipe 2 mayoritas <5 tahun ( 63,3 $\%)$, status IMT adalah Normal ( $35,1 \%)$.

2. Depresi pada pasien wanita diabetes mellitus tipe 2 di Puskesmas Sibela Kota Surakarta(n=60) 
Pada bagian ini disajikan hasil penelitian mengenai depresi pada pasien wanita diabetes mellitus tipe 2 di Puskesmas Sibela Kota Surakarta.

Tabel 2. Analisis depresi pada pasien wanita diabetes mellitus tipe 2 di Puskesmas Sibela Surakarta (N=60)

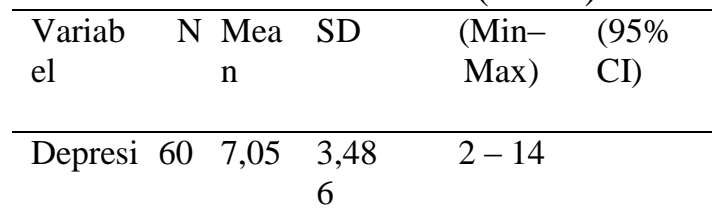

Hasil analisis pada tabel 4-2 menunjukkan bahwa dari 60 pasien rerata depresi adalah 7,05 dengan standar deviasi 3,486, depresi seluruh responden yang terendah 2 dan yang tertinggi 14. Hasil estimasi interval dengan tingkat kepercayaan $95 \%$ disimpulkan bahwa depresi responden seluruhnya berada diantara normal dan abnormal

Tabel 3. Distribusi frekuensi depresi pada pasien wanita diabetes mellitus tipe 2 di Puskesmas Sibela Kota Surakarta (N $=60)$.

\begin{tabular}{cccc}
\hline Variabel & & $\mathrm{N}$ & $\%$ \\
\hline Depresi & Normal & 36 & 60 \\
& Batas Abnormal & 7 & 11,7 \\
& Abnormal & 17 & 28,3
\end{tabular}

Dari tabel 3 diatas dapat diketahui bahwa depresi pada pasien wanita diabetes mellitus tipe 2 di Puskesmas Sibela Surakarta 17 orang $(28,3 \%)$ sedangkan sebagian dalam kondisi normal 36 orang $(60 \%)$

3. Kecemasan pada pasien wanita diabetes mellitus tipe 2 di Puskesmas Sibela Kota Surakarta(n=60)

Pada bagian ini disajikan hasil penelitian mengenai kecemasan pada pasien wanita diabetes mellitus tipe 2 di Puskesmas Sibela Kota Surakarta.
Tabel 4. Analisis kecemasan pada pasien wanita diabetes mellitus tipe 2 di Puskesmas Sibela Kota Surakarta $(\mathrm{N}=60)$

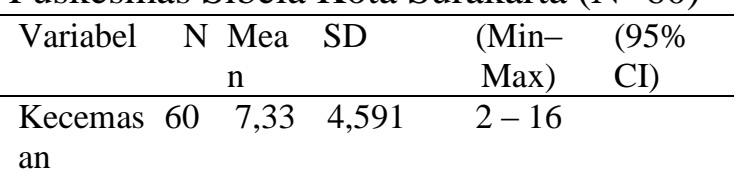
an

Hasil analisis pada tabel 4-4 menunjukan bahwa dari 60 pasien rerata kecemasan adalah 7,33 dengan standar deviasi 4,591, depresi seluruh responden yang terendah 2 dan yang tertinggi 16. Hasil estimasi interval dengan tingkat kepercayaan $95 \%$ disimpulkan bahwa depresi responden seluruhnya berada diantara normal dan abnormal

Tabel 5. Distribusi frekuensi kecemasan pada pasien wanita diabetes mellitus tipe 2 di Puskesmas Sibela Kota

Surakarta( $\mathrm{N}=60)$.

\begin{tabular}{lccc}
\hline Variabel & & $\mathrm{N}$ & $\%$ \\
\hline Kecemasan & Normal & 38 & 63,3 \\
& Batas & 4 & 6,7 \\
& Abnormal & & \\
& Abnormal & 18 & 30 \\
\hline
\end{tabular}

Dari tabel 5 diatas dapat diketahui bahwa kecemasan terjadi pada pasien wanita diabetes mellitus tipe 2 di Puskesmas Sibela Surakarta 18 orang ( $30 \%)$ sedangkan sebagian dalam kondisi normal 38 orang ( $63,3 \%)$

4. Fungsi seksual pada pasien wanita diabetes mellitus tipe 2 di Puskesmas Sibela Surakarta(n=60)

Pada bagian ini disajikan hasil penelitian mengenai fungsi seksual pada pasien wanita diabetes mellitus tipe 2 di Puskesmas Sibela Surakarta. 
Tabel 6. Analisis fungsi seksual pada pasien wanita diabetes mellitus tipe $2 \mathrm{di}$ Puskesmas Sibela Surakarta $(\mathrm{N}=60)$

\begin{tabular}{cccccc}
$\begin{array}{c}\text { Variabe } \\
1\end{array}$ & N & Mean & SD & $\begin{array}{c}\text { (Min- } \\
\text { Max })\end{array}$ & $\begin{array}{c}(95 \% \\
\text { CI })\end{array}$ \\
\hline Fungsi & 60 & 23,268 & 9,327 & $2,0-$ & \\
seksual & & & 5 & 34,2 & \\
\hline
\end{tabular}

Hasil analisis pada tabel 6 menunjukan bahwa dari 60 pasien rerata fungsi kecemasan menurut Female Sexual Function Index adalah 23,268 dengan standar deviasi 9,3275 Indeks fungsi seksual seluruh responden yang terendah 2,0 dan yang tertinggi 34,2. Hasil estimasi interval dengan tingkat kepercayaan $95 \%$ disimpulkan bahwa indeks fungsi seksual responden seluruhnya berada diantara disfungsi dan tidak disfungsi

Tabel 7. Distribusi frekuensi fungsi seksual pada pasien wanita diabetes mellitus tipe 2 di Puskesmas Sibela Kota Surakarta $(\mathrm{N}=60)$.

\begin{tabular}{cccc}
\hline & Variabel & $\mathrm{N}$ & $\%$ \\
\hline $\begin{array}{c}\text { Fungsi } \\
\text { seksual }\end{array}$ & $\begin{array}{c}\text { Disfungsi } \\
\text { seksual } \\
\text { Tidak disfungsi } \\
\text { seksual }\end{array}$ & 32 & 53,3 \\
& 28 & 46,7 \\
\hline
\end{tabular}
bahwa pasien wanita diabetes mellitus tipe 2 di Puskesmas Sibela Surakarta yang mengalami disfungsi seksual adalah 32 orang $(53,3 \%)$ sedangkan sebagian dalam kondisi normal 28 orang $(46,7 \%)$

5. Hubungan tingkat depresi dan disfungsi seksual pada pasien Wanita diabetes mellitus tipe 2 di Puskesmas Sibela Surakarta $(\mathrm{n}=60)$

Pada bagian ini disajikan hasil penelitian mengenai hubungan antara tingkat depresi dengan disfungsi seksual pada pasien wanita diabetes mellitus tipe 2 di Puskesmas Sibela Surakarta, pada tabel 8 .
Tabel 8. Hubungan antara depresi, kecemasan dengan disfungsi seksual pada pasien wanita diabetes mellitus tipe 2 di Puskesmas Sibela Kota Surakarta(n=60)

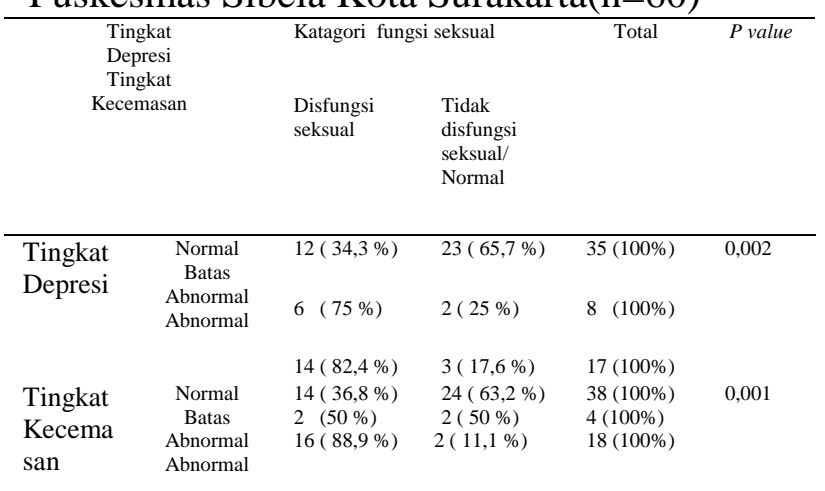

Tabel 8 menunjukan hasil analisis hubungan antara depresi dengan disfungsi seksual pada wanita diabetes mellitus tipe 2. Hasil uji statistik diperoleh ada hubungan $\quad(0,002<0,05), \quad$ tentang hubungan antara kecemasan dengan disfungsi seksual diperoleh hasil bahwa ada hubungan $(0,001<0,05)$.

\section{PEMBAHASAN}

Hasil penelitian diperoleh data jumlah responden sebanyak 60 orang pada kelompok umur berkisar 45 - 55 tahun, pekerjaan Tidak Bekerja (80 \%), mayoritas pendidikan terakhir pasien SMA $(38,3 \%)$, lama menderita diabetes mellitus tipe 2 mayoritas < 5 tahun ( 63,3 $\%)$, status IMT adalah normal ( $35,1 \%)$.

Berdasarkan hasil analisis data depresi didapatkan data mean sebesar 7,05 dengan SD 3,486 dan persebaran depresi responden terendah 2 dan tertinggi 14 yang berarti kondisi depresi pasien berada di antara normal dan abnormal dengan distribusi frekuensi depresi normal 36 orang (60\%), batas abnormal 7 orang $(11,7 \%)$ dan abnormal 17 orang $(28,3 \%)$ dan dari hasil analisis data kecemasan didapatkan data mean sebesar 7,33, 
standar deviasi 45,91 dan persebaran depresi responden terendah 2 dan tertinggi 16 yang berarti kondisi depresi pasien berada di antara normal dan abnormal dengan distribusi frekuensi depresi normal 38 orang $(63,3 \%)$, batas abnormal 4 orang $(6,7 \%)$ dan abnormal 18 orang $(30 \%)$

Hal ini dibuktikan dengan teori bahwa kesehatan merupakan sesuatu yang sangat berharga, dan yang diharapkan oleh setiap individu dalam menjalani kehidupannya, harapan ini terkadang putus di tengah jalan, karena tanpa disadari berbagai penyakit dapat dialami oleh setiap individu. Seringkali berbagai penyakit kronis maupun akut, dapat menyebabkan kematian. Menurut Sarafino (1998) salah satu penyebab kematian adalah penyakit diabetes mellitus (DM). Diabetes Melitus sendiri dapat menimbulkan depresi yang ditandai dengan kehilangan minat, pengurangan energi, menurunkan harga diri dan ketidakmampuan untuk mengalami kesenangan seperti mudah tersinggung dan penarikan diri secara sosial, yang dapat mengganggu kemampuan diri untuk membentuk dan memelihara hubungan intim.

Menurut penelitian (Waleed, 2014) yang dilakukan di Palestina bahwa kebanyakan pasien yang menderita depresi adalah perempuan, memiliki banyak penyakit, pengangguran, pendidikan yang rendah, rendahnya kepatuhan terhadap pengobatan, dan individu yang nilai BMI nya abnormal. selanjutnya, berdasarkan hasil analisis multivariat yang dilakukannya hanya pendidikan yang rendah, pengangguran, dan memiliki banyak penyakit, dan rendahnya tingkat kepatuhan terhadap pengobatan yang memiliki nilai yang signifikan dibanding yang lain

Komplikasi diabetes mellitus tipe 2 sangat berkaitan dengan depresi begitu juga sebaliknya. Disfungsi ereksi adalah salah satu predictor terkuat dari komplikasi diabetes mellitus tipe 2 dengan depresi menurut De groot et al (2001) dan Lustman et al (2000). Menurut Holt, R.I.(2014) dalam penelitiannya bahwa, populasi umum yang memiliki faktor resiko untuk depresi pada diabetes mellitus adalah wanita, status melahirkan, masalah ekonomi, dan memiliki tingkat kegiatan rendah.

Dampak kesehatan di masyarakat menurut hasil penelitian epidemiologi DM di Indonesia menunjukkan angka prevalensi sebesar 1,5-2,3\% pada penduduk berusia lebih dari 15 tahun. Berdasarkan pola pertambahan penduduk saat ini diperkirakan pada tahun 2020 akan ada 3,56 juta pasien DM dengan prevalensi $2 \%$. Peningkatan pendapatan perkapita dan perubahan gaya hidup menyebabkan peningkatan prevalensi penyakit degeneratif seperti penyakit jantung koroner, hipertensi, hiperlipidemia, dan DM (Fisher, Thorpe, McDeVellis, \& DeVellis, 2007; Suyono, 2007)

Dibandingkan dengan penderita penyakit lainnya, penderita DM berisiko lebih banyak dan jauh lebih besar terhadap gangguan depresi. DM dan depresi mempunyai hubungan sebab akibat. Pertama, depresi akan lebih parah dua kali lipat jika diderita oleh individu dengan DM, dibandingkan dengan penderita lain depresi yang diderita oleh penderita penyakit lain selain diabetes hanya mencapai 11\%-15\% (Kinder, Katon, Ludman, Russo, Simon, \& Lin, 2006) 
Kedua, prevalensi depresi mungkin lebih tinggi pada pasien DM yang memiliki komplikasi ganda. Depresi pada pasien DM sering tidak terdeteksi, dan depresi merupakan penghalang utama terhadap manajemen diabetes yang efektif

Diabetes juga terkait dengan berbagai komplikasi kronik. Sebagai contoh masalah seksual pada wanita dengan penyakit kronik sering luput dari perhatian. Hal ini kemungkinan karena fungsi seksual pada wanita masing sering dihubungkan dengan fungsi reproduksi dan tidak membahas tentang kepuasan seksual.

Pada laki-laki penderita diabetes, kejadian disfungsi seksual lebih tinggi dibanding dengan laki-laki yang tidak menderita diabetes. Seperti halnya pada laki laki, maka pada wanita kemungkinan juga terjadi hal serupa

Disfungsi seksual dapat timbul dari kondisi fisik (misal gangguan peredaran darah dapat menyebabkan disfungsi ereksi pada pria) dan dari faktor psikologis seperti stres dan kecemasan akibat penyakit, kekhawatiran mengenai performa seks, problem perkawinan, depresi, perasaan bersalah lebih memengaruhi kejadian disfungsi seksual pada wanita. Selain itu, faktor lain terkait dengan disfungsi seksual termasuk tidak adanya pasangan seksual, dan tingkat kecemasan yang dialami oleh wanita.

Disfungsi seksual wanita merupakan penyakit yang disebabkan oleh berbagai faktor, terdiri dari faktor interpersonal, sosial, psikologis, biologis. Faktor psikologis seperti depresi dan kecemasan berhubungan kuat dengan terjadinya disfungsi seksual pada wanita. Faktor risiko biologis terdiri dari beberapa kondisi medis, seperti gangguan urogenital, gangguan saraf, gangguan endokrin, gangguan kardiovaskular, gangguan dasar panggul, menopause, kehamilan, obesitas; dan obat-obatan.

\section{KESIMPULAN DAN SARAN}

1. Ada hubungan antara depresi dengan disfungsi seksual pada wanita diabetes mellitus tipe 2 dengan nilai $p=0,002$ ( $p<0,05)$.

2. Ada hubungan antara kecemasan dengan disfungsi seksual dengan nilai $p=0.001(p<0,05)$.

Disarankan pada dosen yang melakukan pengabdian masyarakat dapat melakukan pengabdian masyarakat khususnya terkait dengan penanganan kecemasan dan depresi sebagai dampak psikologis DM tipe 2 pada wanita. Bagi Wanita penderita diabetes mellitus tipe 2 disarankan untuk selalu memelihara dan meningkatkan kemampuannya dalam mengatasi masalahnya baik dampak fisik maupun psikologis dari menderita diabetes mellitus tipe 2 .

\section{DAFTAR RUJUKAN}

Fisher, E. B., Thorpe, C. T., DeVellis, B. Mc., \& DeVellis, R. F. (2007). Healthy coping, negative emotions, and diabe-tes management: A systematic review and appraisal. The Diabetes Educator, 33, 1080-1095.

Holt, R.I. , de Groot,M., and Golden, S.H. (2014). Diabetes and Depression.Curr Diab Rep; 14(6): 491. doi: 10.1007/s11892-014-04913. Avaliable https://www.ncbi .nlm.nih.gov/pmc/articles/PMC44760 48/

Kinder, L.S., Katon, W.J. Ludman, E., Russo, J., Simon, G., Lin, E.H.B. (2006). Improving depression care in 
patients with diabetes and multiple compli-cations. Journal General Medic, 21, 1036-1041.

Lustman PJ, Clouse RE. (2002). Treatment of depression in diabetes: impact of mood and medical outcome. J Psychosom Res.;53:917924.

Notoatmodjo, S. (2007). Promosi Kesehatan dan Ilmu Perilaku. Jakarta : Rineka Cipta.

Rosen, R., Brown, C., Heiman, J., Leiblum, S., Meston, C., Shabsigh, R., Ferguson, D., dan D'agostino, R. (2000). The Female Sex ual Function Index (FSFI): A Multidimens ional Self-Repor $t$ Ins trument for the As ses sment of Female Sexual Function. Journal of Sex \& Marital Therapy, 26:191-208.

Roupa, Z., Koulouri, A., Sotiropoulou, P., Makrinika, E., Marneras, X., Lahana, I., dan Gourni, M. (2014). Anxiety and depression in patients with type 2 diabetes mellitus, depending on sex and body mass index. Health Science Journal

Sarafino, E. P. (1998). Health Psychology: Biopsychosocial Intervention, Third Edi-tion, New York Willey \& Sons. Inc.

Suyono, S. (2007). Kecenderungan pening-katan jumlah penyandan diabetes. Dalam Soegondo, S., Soewondo, P., \& Subekti, I. (Ed). Penatalaksanaan Dia-betes Melitus Terpadu. Jakarta: Pusat Diabetes dan Lipid RSUP Nasional Dr. Cipto Mangunkusumo, Fakultas Kedokteran Universitas Indonesia, bekerjasama dengan Departemen Kesehatan RI dan WHO.

Waleed, M. S. (2014). Prevalence of depression among people with type 2 diabetes mellitus: a cross sectional study in Palestine. BMC Public Health201414:163.

https://doi.org/10.1186/1471-245814-163.

Witasari U, Rahmawaty S, Zulaekah S. (2009). Hubungan Tingkat Pengetahuan, Asupan Karbohidrat dan Serat dengan Pengendalian Kadar Glukosa Darah pada Penderita Diabetes Melitus Tipe 2. Jurnal Penelitian Sains \& Teknologi,10(2):130-8.

Zigmond, AS; Snaith, RP (1983). "The hospital anxiety and depression scale". ActaPsychiatrica

Scandinavica. 67 (6): $361-$ 370. doi:10.1111/j.1600$\underline{0447.1983 . t b 09716}$ 